\title{
UMA COMPREENSÃo FenOMENOLÓGICO-HERMENÊUTICA DAS COMPULSÕES NA ATUALIDADE
}

\author{
Ana Maria Lopez Calvo de Feijoo ${ }^{\star}$; Carolina Freire Dhein
}

Universidade do Estado do Rio de Janeiro, Rio de Janeiro, RJ, Brasil

\begin{abstract}
Resumo
A proposta desse estudo é trazer outro modo de pensar as compulsões além daquela que as interpreta como algo da ordem de uma subjetividade encapsulada. Esse outro modo consiste em trilhar um caminho que denominamos de fenomenológicohermenêutico. Acreditamos, com isso, poder abrir a possibilidade de se romper com os modelos previamente legitimados no campo da psicologia. Para tanto, procederemos a uma análise das compulsões nos pressupostos metodológicos da fenomenologia hermenêutica de Heidegger, partindo da ideia de que a existência humana se constrói na articulação copertinente com o mundo e viabilizando, assim, uma interpretação das compulsões no horizonte histórico da técnica.
\end{abstract}

Palavras-chave: compulsões; fenomenologia; hermenêutica.

\section{A PHENOMENOLOGICAL-HERMENEUTICS COMPREHENSION OF COMPULSIONS TODAY}

\begin{abstract}
The proposal of this study is to think about another way of thinking the compulsions beyond that which interprets this phenomenon as something on the order of subjectivity. This other way is to follow at a new path that here called phenomenological-hermeneutics. It to begin the templates previously legitimized in the field of psychology. We will review the compulsions and its disorders, inspired by the methodological assumptions of hermeneutics phenomenology of Heidegger. Your idea is that human existence is building in conjunction with the world, thus, an interpretation of the compulsions outside the contours of historical horizon of the technique.
\end{abstract}

Keywords: compulsions; phenomenology; hermeneutics.

\footnotetext{
^Endereço para correspondência: Universidade do Estado do Rio de Janeiro, Departamento de Psicologia Clínica, Instituto de Psicologia. Rua São Francisco Xavier, 524 - Maracanã. 20550013

- Rio de Janeiro, RJ - Brasil.E-mail: ana.maria.feijoo@gmail.com, carolinadhein@hotmail.com
} 
As compulsões vêm sendo amplamente discutidas no terreno da psicologia, principalmente pela apropriação de um discurso técnico-cientificista, que busca explicá-las a partir de categorias diagnósticas desdobradas de forma cada vez mais específicas. Com isso, a psicologia, com suas teorias e técnicas, pretende dar conta da complexidade desses fenômenos, agrupando, classificando e explicando a experiência da compulsão como um desvio ou patologia, que se encontra em uma interioridade, privilegiando ora aspectos de ordem biológica, ora da ordem do psíquico, ou ainda explicações de ordem exclusivamente social. No entanto, diferentes estudiosos da psicologia vêm repensando, e até mesmo combatendo essa dicotomia interior e exterior, com as consequentes categorias identificatórias, que acabam por responsabilizar única e exclusivamente o indivíduo pelas suas mazelas e apartando o mundo dessa dinâmica.

Assim, acreditando que é possível pensar o homem a partir de um referencial outro que não o da tradição dominante da psicologia, nós tentaremos apreendê-lo em uma perspectiva fenomenológica - hermenêutica, como uma existência em uma dinâmica e fluxo incessantes. Essa compreensão torna-se relevante por nos convidar a suspender os caminhos já previamente estabelecidos, oferecendo-nos uma nova possibilidade de pensar o modo compulsivo como uma atmosfera de nosso tempo. Com isso, abre-se outra possibilidade de compreensão do fenômeno da compulsão e suas expressões, além daquela que concebe o fenômeno como um desvio patológico em um referencial subjetivista e determinista.

Com relação à hegemonia do pensamento psicológico com ênfase no privado e particular, alguns estudiosos do tema defendem a ideia de como o espírito do mecanicismo, originado no século XVII, revolucionou de forma definitiva e ampla a lógica do pensamento ocidental, não ficando restrito apenas ao campo das ciências naturais. Schultz, D. e Schultz, S. (1992[1969]) nos dizem que tudo, inclusive o homem, passa a ser objeto para a nascente ciência experimental, ficando o mundo reduzido a uma realidade objetiva e determinista da técnica que calcula. Figueiredo (1994) refere-se a influência do iluminismo sob a interpretação individualista da vida social e ainda defende que "a subordinação do conhecimento científico à utilidade, à adaptação e ao controle, bem como a modelação da prática científica pela ação instrumental alcançaram realce cada vez maior" (FIGUEIREDO, 2012, p.12). Mancebo (2004, p. 40) afirma veemente que o conceito de indivíduo é uma construção da modernidade e que "o ideário tecnocrático e disciplinar desenvolve-se como uma versão das ideias liberais, dando-lhes, no entanto, novos rumos, ao exigir-lhes maior interesse, eficiência e utilidade". Vemos, com isso que há mais de três séculos, a sociedade ocidental iniciou, de forma radical, um modo de se relacionar com o mundo, pautado na crença do domínio do homem sobre a natureza, conduzindo-o ao domínio de todas as esferas de sua existência. É notável como as ideias de controle, exploração, autonomia e liberdade, herdadas da noção de subjetividade moderna, têm se feito presentes como norteadoras do comportamento do homem moderno.

Ainda sobre o homem moderno, Mancebo (2004) acrescenta que a herança do liberalismo, trazida pelas ideias do iluminismo e do romantismo, entregou ao homem a noção de indivíduo autônomo, capaz de exercer sua condição de liber- 
dade e interioridade, colocando o mundo em favor de suas necessidades. A autora afirma ainda que, em decorrência de tais valores, a sociedade contemporânea desembocou num individualismo exacerbado.

Levado a encontrar o sentido do mundo a partir de si próprio, o indivíduo volta-se para a elaboração cada vez mais refinada de sua própria individualidade, fecha-se em sua particularidade, considerando a liberdade principalmente como a possibilidade de considerar seus interesses privados. (MANCEBO, 2004, p.46)

Mancebo (2004) prossegue sua reflexão, colocando em cena também a herança do pensamento moderno na Psicologia, disciplina essa que é fruto desse mesmo horizonte histórico. Segundo a autora, muitas recentes discussões no campo da psicologia vêm sendo travadas a respeito da dicotomia herdada do positivismo entre indivíduo/sociedade, desencadeando um saber amparado em uma categoria a priori e, portanto, não problematizada. A autora alerta que as noções de indivíduo, bem como o conhecimento que travamos a seu respeito são construções oriundas de contextos culturais e historicamente demarcados. Alerta-nos, assim, que os aspectos da subjetividade não podem ser compreendidos desligados da orientação social em que são constituídos.

Bauman (1999, p. 48), um dos sociólogos que exaustivamente se dedicam a pensar as consequências do pensamento moderno na sociedade contemporânea, contribui com as ideias antes expostas, afirmando que

A ciência moderna nasceu da esmagadora ambição de conquistar a natureza e subordiná-la às necessidades humanas. A louvada curiosidade científica que teria levado os cientistas 'aonde nenhum homem ousou ir ainda' nunca foi isenta da estimulante visão de controle e administração, de fazer as coisas melhores do que são (isto é, mais flexíveis, obedientes, desejosas de servir).

Ao discorrer acerca da trajetória da Psicologia Social, especificamente, Álvaro e Garrido (2006) oferecem uma reflexão crítica do percurso desse campo de saber, que traz em sua história visões dicotomizadas a respeito dos vínculos entre indivíduo e sociedade. A psicologia social, segundo esses autores ou prioriza o individual, ou dá um grande destaque ao social. Álvaro e Garrido (2006) enfatizam que o estudo do comportamento humano só faz sentido com referência ao contexto social ao qual está circunscrito e, por isso, a psicologia social deve consistir na articulação dos níveis tanto psicológicos quanto sociológicos. No entanto, parece que esses autores ao referir-se aos dois níveis de articulação, ainda mantém uma dicotomia e a ideia de saber disciplinar.

Na tentativa de encontrar uma posição crítica com relação à dicotomia indivíduo e social, de modo a não mais referir-se a uma dualidade ou polarização, é que vamos tomar, para nossa discussão sobre as compulsões na atualidade, a fenomenologia e a hermenêutica. A escolha da fenomenologia se deve ao fato que 
a sua premissa é a de que devemos suspender todas as hipostasias, sejam as que priorizam o indivíduo, seja as que priorizam o social (FEIJOO, 2011). Quanto à eleição da hermenêutica heideggeriana, isso se deve ao fato de que com a hermenêutica, Heidegger pretendia superar toda a dicotomia da relação sujeito - objeto, referindo-se ao brotar da existência sob o solo de sua historicidade (STEIN, 1983).

Para pensar as compulsões, na atualidade, em uma tentativa de não recair na dicotomização social-individual, é que tomaremos como caminho para esta investigação a fenomenologia-hermenêutica, tal como desenvolvida por Heidegger, em suas obras filosóficas, dentre elas Ser e tempo (1989[1927]). Stein (1983) indica a possibilidade desse método investigação dos fenômenos existenciais, inclusive, afirmando que esse foi o caminho pelo qual Heidegger conduziu o seu pensamento. E, desse modo, em um caráter especulativo e totalizador, por essa via podemos alcançar a superação do pensamento da subjetividade e o desvelamento da história do ser.

Atentos a essas considerações precedentes é que nos aproximamos das contribuições do pensamento fenomenológico-hermenêutico. Acreditamos que esse método oferece uma proposta de radical rompimento com o modo tradicional de compreensão do homem e do mundo. Assim como a fenomenologia assumida por Heidegger, com inspiração em Husserl (2007[1901]) - fundador formal da fenomenologia, expulsado os conteúdos da consciência e definindo-a como uma relação intencional com o mundo - radicaliza o conceito de intencionalidade e rompe com as principais dicotomias herdadas da tradição moderna, de interior e exterior, particular e universal. Assim, Heidegger postula que o modo de ser do homem é abertura de sentido. Tal abertura consiste na ausência de qualquer determinação a priori capaz de definir o homem, e é condição para que a existência humana se constitua em uma unidade ontológica, chamada por ele de Dasein ou ser-aí, indicando que homem e mundo são, portanto, cooriginários e constituem uma totalidade inseparável. O homem é homem no mundo e se define nessa relação mesma. E é dessa forma que partiremos para uma análise das compulsões e suas diferentes expressões, inclusive daquilo que denominaremos de transtornos compulsivos.

\section{O MÉTODO: ROMPIMENTO COM A DICOTOMIA SUJEITO-OBJETO}

A filosofia moderna, ao proceder a uma cisão do real, estabelece diversas oposições. Trata-se das dicotomias metafísicas, nas quais um dos polos, o sujeito, posiciona, condiciona e justifica o outro polo, o objeto. O sujeito é tomado como previamente constituído e, portanto, substantivado. Assim, a metafísica da subjetividade pressupõe que é desses dois polos que a relação se origina. Logo o que há de mais originário é o sujeito por um lado e o objeto por outro. E foi nesse paradigma que a psicologia quase que hegemonicamente se constituiu.

Franz Brentano (1995[1903]), em A psicologia do ponto de vista empírico, na tentativa de elevar a psicologia ao nível de uma ciência autônoma, desliga-se da psicologia com bases na fisiologia e vai buscar em Aristóteles os argumentos dos quais necessitava para elaborar uma psicologia que sustentasse seu próprio objeto com total independência dos fatos biológicos ou sociais. Para Brentano 
importa o ato psicológico, a intencionalidade, propondo, assim, a indissociabilidade entre pensamento e ação. Husserl (2007[1901]) dá continuidade ao projeto de Brentano, defendendo a tese de que o mais originário é a própria relação. E o sujeito e o objeto derivam dessa relação, que é a própria intencionalidade. Heidegger (1989[1927]) em seus estudos sobre o ser-aí radicaliza essa noção husserliana, porém introduz ao real outro elemento que é a história. Daí, ele afirmar que seu método consiste em uma fenomenologia-hermenêutica.

Em Heidegger (2006[1929]) comportamento e história relacionam-se intimamente. Todo e qualquer comportamento se dá por condições próprias a um horizonte histórico. Daí que interpretar as compulsões em uma perspectiva intimista acaba por conduzir a equívocos. Por esse motivo, a proposta aqui consiste em investigar a cooriginalidade do modo compulsivo do homem contemporâneo e as condições históricas que o circunscrevem. Como anteriormente apresentado, é fundamental na perspectiva da existência o rompimento com toda e qualquer dicotomia. Vamos então explanar de que modo as filosofias da existência, especificamente Heidegger, desenvolveram a questão.

\section{A TEMÁtica EXISTENCIAL: ROMPIMENTO COM A DICOTOMIA UNIVERSAL E SINGULAR}

A tentativa de resolver as dicotomias presentes na epistemologia encontra-se na filosofia existencial, desde Kierkegaard (1813-1855). Esse filósofo posiciona-se acerca desse tema, afirmando que onde está a multidão encontramos o indivíduo e que uma multidão não se faz sem indivíduos (KIERKEGAARD, 1988[1846]). Husserl (2007[1901]), em suas Investigações lógicas, procede de forma a resolver a dicotomia individual e universal, intuindo, assim, o espaço de constituição do eu, que ele mesmo denominará de intencionalidade. Jean-Paul Sartre (2002[1960]), filósofo existencialista, contribui de forma significativa para essa temática em sua obra filosófica Questão de Método. Inspirado de forma crítica pelo materialismo histórico-dialético de Marx, Sartre ressalta que o homem, por projetar sua existência no mundo, existe em um movimento dialético entre o singular e o universal. Para Sartre, o homem é uma apreensão sempre singular das condições de possibilidade demarcadas pelo horizonte histórico em que está situado. E dessa forma, o pensador vai além e afirma por ser dialético, o homem faz e é feito pela História. É com o Heidegger (1989[1927]) tardio, no entanto, que a tentativa de resolução dessa questão se radicaliza, de modo que a tematização do sentido do ser, iniciada em Ser e tempo acerca do ser-aí (Dasein), afasta-se do ser e mantém o "aí". "Aí" como espaço onde há o total e radical entrelaçamento do eu e do mundo. Existencial deve, então, ser compreendido, tal como tomado pelos filósofos da existência, como o espaço de realização do existir em sua condição de finitude, que diz respeito às possibilidades mais originais daquele que existe no seu encontro, também originário, com o mundo. E é nesse horizonte de sentido que iremos discutir as compulsões na era da técnica.

Heidegger (1989[1927]), nos convida a compreender homem e mundo não como instâncias separadas, mas sim como uma relação cooriginária, nem o homem, nem o mundo podem ser analisados de forma privilegiada, ambos formam

Fractal, Rev. Psicol., v. 26 - n. 1, p. , Jan./Abr. 2014 
uma totalidade. Buscando desconstruir uma perspectiva subjetivista e antropocêntrica, Heidegger (1989[1927]) nos dirá que o homem não possui qualquer caráter de interioridade. Sua existência se dá na abertura de sentido articulada ao horizonte no qual está mergulhado. Dessa forma, o pensador nos ensina que a compreensão dos fenômenos humanos acontece de forma fenomenológico-hermenêutica, pois sendo homem e mundo uma totalidade, só podemos compreendê-lo a partir de um horizonte prévio de sentido. Feijoo (2010, p. 156) acrescenta "que o círculo hermenêutico em Heidegger abarca a ideia de que não há possibilidade interpretativa existencial alguma que não se dê em um horizonte fático de sentido". Significa dizer que toda compreensão dos fenômenos humanos insere-se em uma compreensão histórica.

\section{COMPREENSÃO FENOMENOLÓGICO - HERMENÊUTICA DAS COMPULSÕES}

São diversas as formas de expressão da compulsão na era contemporânea, seja na esfera afetiva, profissional, alimentar, mercadológica, dentre outras. E também são suas diferentes formas de expressão desistência, descompromisso, ócio, tédio e temor. Tanto com relação ao fenômeno da insistência por meio das compulsões, como o da desistência por meio do tédio, como o de controle por meio ao temor, Heidegger nos convida, antes de calcular para descobrir suas causas e tratamentos, a refletir, meditar para além de uma visão fragmentada entre indivíduo e mundo. E, ainda, ele nos aponta para a necessidade de um olhar atento para o horizonte de sentido que atualmente demarca as condições de possibilidade para o surgimento de experiências compulsivas e suas diferentes expressões, circunscritas pelas determinações históricas que nos cercam. Encontramo-nos em um mundo com orientações que solicitam, a todo o momento, à produtividade $\mathrm{e}$ à ação. As referências à valorização do individualismo aliada ao conhecimento técnico científico moderno podem ter possibilitado ao homem se conceber como autônomo, em um mundo em que tudo passa a ser reduzido ao terreno da instrumentalidade? No horizonte histórico, denominado por Heidegger (2002[1954]) de era da técnica, o homem autônomo da modernidade passaria a homem autômato, já que não mais ocupa o centro da atenção, cabendo esse lugar à tecnologia, que opera por meio da lógica da produtividade, funcionalidade, utilidade, exploração, estocagem e descartabilidade? Dessa forma, caberia pensar se o modo de ser compulsivo que se apresenta na atualidade, pode ser compreendido a partir desse horizonte histórico técnico que se desvela ao modo dos excessos? Modo esse que requisita ao homem uma orientação de comportamento que atenda de modo autômato aos apelos de produtividade, serventia e descartabilidade. Na tentativa de responder a tais questionamentos, pretendemos investigar outros modos de como o fenômeno do transtorno compulsivo e suas diferentes expressões podem ser pensados. E, assim, não mais interpretá-los apenas como um desvio que se encontra no interior de uma subjetividade, mas também como um modo de ser possível inserido no horizonte técnico contemporâneo.

Os fenômenos dos transtornos compulsivos e suas diferentes expressões presentes em muitas das atividades humanas, serão pensados, neste trabalho, para além dos moldes de uma psicologia clínica, com ênfase no caráter privativo da existên- 
cia. Traremos à discussão temas já estudado pelas filosofias, tais como o tédio e o temor, que muito podem contribuir com a elucidação das compulsões, como marca do comportamento do homem em nosso tempo. Tanto o tédio como o temor, sem dúvida, tonalidades afetivas fundamentais, marcadamente presentes na contemporaneidade, muito se atrelam ao modo compulsivo das situações mundanas. Tanto no que se refere ao seu agir quanto ao seu pensar, o homem se constitui por meio das ações compulsivas próprias do horizonte técnico em que nos encontramos. Destacamos, então, a compulsão como um traço do comportamento em geral.

\section{HEIDEGGER: TÉCNICA E COMPULSÃo}

No ensaio intitulado "A questão da técnica", Heidegger (2002[1954]) nos convida a refletir acerca das determinações presentes no horizonte técnico no qual se constitui o mundo moderno. Ele afirma que há um domínio do pensamento calculante, que ganha expressão, principalmente, a partir do advento da revolução científica do século XVII. Esse modo dominante de pensar restringiu todas as outras possibilidades de pensar, inclusive, obscureceu a possibilidade de aparecimento do pensamento que medita (HEIDEGGER, 1959). Para esse pensador, as maneiras de exercer a técnica na modernidade, ou seja, através da física e da matemática, não ficaram restritas apenas a um modo de pensar, característico desses campos de saberes, mas também, ao nosso modo de ser e agir que nos caracteriza enquanto civilização. Homem e mundo passam, então, compreendidos a partir da lógica da instrumentalidade. O principal alerta do filósofo do Dasein será sobre o modo como a sociedade moderna descortina o mundo. Esse desvelar pela intervenção técnica, constitui-se exclusivamente como um instrumento, meio, para atingir fins, obscurecendo outras orientações possíveis.

Para Heidegger (2002[1954]) o problema da técnica consiste justamente em sua essência compulsiva. A técnica tem em si um traço compulsivo fundamental que caracteriza o nosso tempo. No mundo da técnica, a ação excessiva é a lei, princípio de determinação de todas as coisas. As determinações do mundo da técnica apontam para uma incessante projeção para além de todas as configurações que a técnica conquista. Dado o caráter impessoal das configurações técnicas, ocorre um total descompromisso. A incessante projeção juntamente com o descompromisso com a produção e suas consequências traz uma aceleração infinita, desaparecendo todo e qualquer limite. Não há nenhuma trava que possa funcionar como uma barreira para a aceleração e abundância das produções oriundas da técnica. O homem por seu caráter de indeterminação, diz Heidegger (1989[1927]), tende no início e na maioria das vezes a tomar as referências do mundo em que ele se encontra. E, assim, absorvido por essa atmosfera, age incessantemente em uma automatização total do comportamento com relação ao sujeito do comportamento. Heidegger, na contramão das interpretações modernas, que pressupõem que a compulsividade diz respeito a uma subjetividade fissurada, afirma que a questão da compulsão tem uma relação direta com o nosso horizonte "epocal" onde reinam as referências da técnica. E o horizonte histórico da técnica, em que nos encontramos, com a ênfase na produtividade, é compulsivo. 
Para Casanova (2006), o tédio é justamente esse efeito da técnica em sua incessante movimentação, em que o homem sempre se encontra lançado para o momento a seguir, perdendo totalmente a articulação com o seu sentido, em uma atmosfera da compulsão. No agir sem parar, desarticulado do sentido pelo qual se age, é que se instaura o tédio. O tédio então anuncia o total e radical desinteresse do homem por si mesmo, na medida em que ele mesmo se desvincula, esquece e obscurece outros sentidos possíveis, tomando para si, de modo totalmente restrito, o sentido imprimido pelo mundo da técnica.

Iniciaremos nossos questionamentos com a tonalidade afetiva fundamental do tédio para então discutirmos as compulsões, como um modo possível de abafar essa tonalidade que predomina na época da técnica.

\section{TÉCNICA, TÉDIO E COMPULSÃO}

Segundo Heidegger (2006[1929]), o tédio consiste na tonalidade afetiva fundamental do horizonte histórico em que nos encontramos. A tentativa de obscurecer, aplacar o total desinteresse e esquecimento do ser, consiste no modo em que nós nos encontramos afinados na era da técnica. Na era da técnica acontece que as orientações do mundo ocorrem de forma tal que ela, a técnica, absorve o homem. E assim ele acaba por automatizar totalmente seus atos. O espaço de temporalização do existir do homem se estreita de modo que a sensação é de asfixia. O tempo, ao se afinar com o tempo do mundo, constitui-se por um modo acelerado, nunca para e nem diminui a velocidade. Sem necessários, o homem da era da técnica perde totalmente o interesse por si mesmo e se perde na poeira dos possíveis. Para não se dar conta desse seu destino, ele tenta o quanto pode ter com que se distrair. Kierkegaard (2006[1843]) e Heidegger (2006[1929]) referem-se à distração de todos os tipos, seja pelo excesso de diversão, seja pelo excesso de trabalho, constitui-se no modo de não permitir que o tédio venha e diga, afinal, o que está acontecendo. Assim, nos deparamos com homem compulsivo na atualidade.

A ação, ao se tornar uma repetição incessante, passa a ser definida como compulsiva, já que o sujeito do comportamento não tem mais nenhum controle sobre si. E essa compulsão se materializa em uma série de transtornos, interpretados aqui, não como falhas de uma determinada subjetividade, mas que ousamos denominar de transtornos "epocais". Queremos com isso dizer que o horizonte da compulsão atravessa, hoje, os nossos modos de ser.

\section{OS TRANSTORNOS COMPULSIVOS: CONTROLE, TEMOR E TÉDIO}

Tentaremos então esclarecer a questão do transtorno em uma fenomenologia hermenêutica. Na psicologia tradicional a neurose diz respeito a uma subjetividade encapsulada que carrega em sua interioridade o seu transtorno e, portanto, nela é que repousa toda a responsabilidade pelo modo como conduz a sua vida. Com base em uma psicologia existencial, caminhamos no sentido de entender que o que está em jogo nos transtornos é o choque que se apresenta frente ao indeterminado e a tentativa de controlar essa indeterminação. Como tal tentativa fracassa, podem ocorrer diferentes modos de lidar com a situação. Aqui iremos 
apresentar quatro delas. A primeira é a que denominamos de ação compulsiva que consiste em insistir bravamente, por meio de uma ação incessante. E o que comumente denominamos de determinação. A segunda, na qual o homem fica transtornado frente ao ter que ter o controle a qualquer preço, nós chamaremos de transtorno obsessivo compulsivo. Frente aquilo que esse homem teme, ou seja, a sua vulnerabilidade, ele restringe a gama de possibilidades que se apresentam, e assim, tenta com todas as forças e, ainda, com maior determinação, retomar o controle por diferentes meios frente àquilo que teme. Na terceira, trata-se do desânimo frente à exigência que não cessa, pela qual, muitas vezes, o homem tomado por essa disposição recebe a denominação de ocioso, preguiçoso, improdutivo. E, por fim, este homem em transtorno frente à insistência em sua produtividade, não mais vendo possibilidades, desiste total e radicalmente, assim, abandona-se ao movimento do mundo e temos então a tonalidade do tédio.

Em Heidegger, os transtornos existenciais são comportamentos que promovem um estreitamento do horizonte existencial, de modo a encurtar as possibilidades existenciais. Em Ser e Tempo, Heidegger (1989[1927]) pensa o cotidiano em uma perspectiva do comportamento mediano, no qual permanecemos com a impressão de que temos o controle e agimos de modo a que nada seja mais importante ao que tomar conta daquilo, que de algum modo acreditamos ameaçar nossa existência. E toda vez que temos o anúncio do incontrolável, dispomos de um esforço enorme para retomar o controle. Acontece que nada disso é da ordem do racional. Como diria Sartre (2001[1943]), isso acontece na síntese do projeto, na ordem do pré-lógico, horizonte esse que não pode jamais ser controlado. Por isso podemos arriscar dizer que, na cotidianidade mediana o que mais acontece são modos de ser restritivos, controladores. Ocorre que, ao tentar controlar tudo, esse projeto fracassa, já que na vida nunca é possível ter controle total sobre tudo e todas as coisas. Aquele que vive o transtorno apresenta uma tentativa de controle total, porém em um espaço reduzido. E ao reduzir $\mathrm{o}$ espaço das possibilidades à vulnerabilidade e às ameaças a sua existência, o transtornado acaba por tomar como ameaçadora uma e única possibilidade. Esse espaço restrito traz a ilusão de um controle possível, mas é justo nessa redução que há o transtorno. Na ação compulsiva, o homem insiste em manter tudo sobre controle, mas pode acontecer, ao contrário, a desistência, já que esse homem se dá conta de sua impotência frente ao controle pretendido. E, assim, temos o transtorno como elemento decisivo para o controle, determinação, compulsão ou, ao contrário, para a total e radical entrega, daí a inação, a tristeza e o abandono de toda e qualquer tentativa de criar projetos para a sua existência.

Sartre (2000[1938]) exemplifica essa intuição da indeterminação da existência e seu caráter incontrolável em seu romance $A$ Náusea. Roquentin, principal personagem do romance, desvela pela experiência da Náusea o sentido absurdo da existência. A epígrafe do livro já anuncia de quem se trata Roquentin: "É um rapaz sem importância coletiva. É apenas um indivíduo" (s/p), denotando um homem comum, mergulhado no mundo, como todos os homens. Sendo um historiador, Roquentin reside temporariamente em uma pequena cidade de interior com 
o objetivo de escrever a biografia de um político. Nesse sentido, Sartre procura indicar que o personagem vive de início uma atmosfera controlável e previsível, mergulhado na familiaridade do mundo.

Silva (2004) atenta para o caráter ordenado da História, que, ao ser retratada, só pode se desvelar no passado. Escrever uma biografia, por exemplo, é contar com fatos que já se deram e lançar mão, portanto, de um encadeamento temporal linear. Daí a ideia de controle e previsibilidade. A existência, ao contrário do encadeamento linear das histórias contadas nos livros, acontece na dinâmica temporal do próprio existir. E é na existência mesma, no cotidiano, na relação concreta com o mundo, que Roquentin, aos poucos, suspende a familiaridade com as coisas a sua volta, dando-se conta da injustificabilidade destas, e, consequentemente, a própria existência. Nada é necessário. "Existir é estar presente simplesmente [...]. A contingência não é um falso semblante, uma aparência que se possa dissipar; ela é o absoluto e consequentemente a gratuidade perfeita" (SARTRE, 2000[1938], p. 194). Pela náusea a realidade perde seu caráter de determinação, ou, melhor dizendo, perde sua razão de ser, razão essa no sentido de causalidade.

Vemos, dessa forma, que tanto a náusea como o tédio apontam para a copertença da existência homem-mundo. Se ser é ser-no-mundo, como nos diz Heidegger (1989[1927]), é no mundo, no espaço do existir que se desvela como o repertório de sentidos, que encontramos, de início e na maior parte das vezes, uma familiaridade tal que, ao mesmo tempo em que nos situa, aprisiona. Na era da técnica que calcula, o mundo nos diz que o sentido das ações conclama ao rigor, à segurança. As ações convertem-se em finalidades justificadas em si mesmas, por meio do controle que visa assegurar uma certeza.

Todos esses modos de lida do homem com as determinações do mundo da técnica, Heidegger (2006[1929]) denomina como tonalidades afetivas, que consiste em um espaço que não é nem interior, nem exterior, que sustenta a situação e onde as determinações acontecem. A atmosfera que parece sustentar o transtorno do controle é o temor. O temor relaciona-se com o medo. Heidegger (1989[1927]) diz que o medo torna a rede referencial mais presente e a circunvisão se acirra. Aquilo de que temos medo, torna-nos mais atentos àquilo que previne o acontecimento que tememos. Aparece, assim, a atmosfera de temor.

Pensar no horizonte histórico que determina as nossas ações por meio dos elementos da técnica com a sua atmosfera própria de controle, compulsão, violência ou de entrega, inação e desistência, parece trazer uma outra forma de interpretar os transtornos na atualidade.

\section{Conclusão}

Com essas considerações, abrimos a possibilidade de se pensar o homem como uma totalidade e não mais como a aparente insuperável visão subjetivista ou objetivista, presente no campo da psicologia. Faz-se possível, então, agora, refletirmos acerca do modo de ser compulsivo do homem a partir do horizonte histórico no qual ele se situa. 
Com os apontamentos expostos anteriormente acerca da questão da técnica, desenvolvidos por Heidegger (2002[1954]), percebemos um mundo dominado pelo modo técnico-calculante, no qual tudo é regido pelo viés da instrumentalidade. Pensando a respeito dessa reflexão, Sá e Rodrigues (2008, p. 39) argumentam que "somos cada vez mais convidados a desvelar a natureza como dis-ponibilidade (Bestand): tudo se encontra disponível para ser extraído, transformado, estocado, utilizado, consumido". Também contribuindo para essa reflexão, Feijoo (2008) nos diz que a herança da modernidade desemboca numa atualidade pós-moderna que se desvela de forma ambígua pelo excesso e pelo controle. $\mathrm{O}$ homem, ao mesmo tempo em que deve valorizar a ordem, o método e o controle, é também convidado a comportar-se de forma hedonista, marcado por noções de exploração, serventia e descartabilidade, contexto no qual o consumo pode ser considerado a mais evidente expressão dessa experiência na atualidade.

Lipovetsky (2007) em sua obra A felicidade Paradoxal, também aborda as demandas paradoxais do que chamou de Hipermodernidade. Argumenta que ao mesmo tempo em que há o culto ao bem-estar, aos lazeres e à saúde, vê-se o crescimento da indústria medicamentosa, como também uma impressionante expansão dos distúrbios psíquicos. "A insegurança, a desconfiança, a ansiedade cotidiana crescem na proporção mesma de nosso poder de combater a fatalidade e alongar a duração da vida" (LIPOVETSKY, 2007, p. 55). Para o autor, quanto mais explodem os apetites de aquisição manifestados principalmente pela prática do consumo, mais se agravam os descontentamentos individuais.

$\mathrm{Na}$ era da técnica contemporânea, o modo da instrumentalidade desvelada através do consumo, talvez seja a principal forma de relação do homem com o mundo, uma vez que o consumo na atualidade não se restringe apenas à aquisição de mercadorias, mas se torna a lógica de toda e qualquer relação do homem com seu meio, com outros homens e consigo próprio. Com esse movimento, podemos refletir que o modo de ser compulsivo, tratado neste artigo, pode ser considerado uma marca da sociedade contemporânea. Intimamente relacionado ao convite pelo consumo sem freios, vinculado à ordem do desejo insaciável, às noções de exploração e descartabilidade, a compulsividade ilustra o comportamento do homem contemporâneo nas mais diversas esferas de sua existência. Esse homem come em excesso, trabalha em excesso, medica-se em excesso, compra em excesso. Somos impulsionados a nos comportar compulsivamente na medida em que temos como horizonte uma sociedade que elege como valor a insatisfação constante, estimulada pelas possibilidades de explorações infinitas, ao mesmo tempo em que, a movimentação incessante, tentamos escapar ao tédio.

Assim, tomando como base o pensamento fenomenológico-hermenêutico de Heidegger, apresentamos a possibilidade de interrogar as análises tradicionais no campo da psicologia, principalmente no que tange à compreensão do modo de ser compulsivo. A psicologia, de um modo geral, concebe a compulsão em uma visão psicopatológica, herdada do saber médico-cientificista. Não queremos, com isso, anular a legitimidade dos conhecimentos trazidos pela ciência, nem mesmo desconsiderar que a experiência da compulsão possa tomar formas verdadeiramente patológicas. Inspirados nas palavras de Heidegger (1959, p.

Fractal, Rev. Psicol., v. 26 - n. 1, p. , Jan./Abr. 2014 
23) em seu poético texto Serenidade, "seria insensato investir às cegas contra o mundo técnico", porém, através de um pensamento que medita, ou seja, da reflexão, podemos dizer sim às orientações do mundo técnico, ao mesmo tempo em que podemos dizer não, impedindo que nos absorvam totalmente, transformando-nos em autômatas. Com isso duas reflexões mostram-se pertinentes: embora a compulsão possa se apresentar de formas muito específicas e singulares, parece que hoje assistimos a um aumento significativo de suas expressões. E é essa constatação que nos convida a pensar no caráter mais original desse fenômeno. Com base nos estudos sobre as tonalidades afetivas, discutidas por Heidegger, é que ousamos pensar que o que importa é o horizonte histórico no qual as determinações dos modos de ser do homem acontecem. Horizonte histórico que se descortina ele próprio ao modo compulsivo. Esse ponto nos conduz diretamente a uma segunda reflexão: a importância de atentar para a estreiteza de olhares dicotomizados e apartados de uma compreensão total do homem, ainda muito presentes no campo da psicologia quando esta posiciona sua preocupação com leis instrumentalmente válidas em termos universais ou com interpretações subjetivistas inspiradas em uma ideia de interioridade. 


\section{REFERÊNCIAS}

ÁlVARO, J. L.; GARRIDO, A. Psicologia Social: perspectivas sociológicas e psicológicas. São Paulo: Mcgraw-hill, 2006.

BAUMAN, Z. Modernidade e ambivalência. Rio de Janeiro: J. Zahar, 1999.

BRENTANO, F. Descriptive Psychology (1903). London: Routledge, 1995.

CASANOVA, M. A. Nada a caminho: impessoalidade, niilismo e técnica na obra de Martin Heidegger. Rio de janeiro: Forense Universitária, 2006.

FEIJOO, A. M. L. C. O conflito psíquico na atualidade: compulsão ou hibris? In: FEIJOO, A. M. L. C.; SÁ, R. N. (Org.). Interpretações fenomenológicoexistenciais para o sofrimento psíquico na atualidade. Rio de Janeiro: IFEN, 2008. p. 55-80.

FEIJOO, A. M. L. C. (Org.). Tédio e finitude em uma perspectiva daseinanalítica. In: . Tédio e finitude: da filosofia à psicologia. Belo Horizonte: Fundação Guimarães Rosa, 2010. p. 145-176.

FEIJOO, A. M. L. C. A existência para além do sujeito: a crise da subjetividade moderna e suas repercussões para a possibilidade de uma clínica psicológica com fundamentos fenomenológico-existenciais. Rio de Janeiro: Viaverita, 2011.

FIGUEIREDO, L. C. A invenção do psicológico: quatro séculos de subjetivação 1500-1900. São Paulo: Escuta/EDUC, 1994.

FIGUEIREDO, L. C. Matrizes do pensamento psicológico. Petrópolis, RJ: Vozes, 2012.

HEIDEGGER, M. Serenidade. Lisboa: Instituto Piaget, 1959.

HEIDEGGER, M. Ser e Tempo (1927). Petrópolis, RJ: Vozes, 1989.

HEIDEGGER, M. Aquestão da técnica (1954). In: .Ensaios e conferências. Petrópolis, RJ: Vozes, 2002. p. 11-38.

HEIDEGGER, M. Os conceitos fundamentais da metafisica: mundo, finitude, solidão (1929). Rio de Janeiro: Forense Universitária, 2006.

HUSSERL, E. Investigações lógicas (1901). Lisboa: Centro de Filosofia da Universidade de Lisboa, 2007. 
KIERKEGAARD. S. O lo uno o lo otro: um fragmento de vida (1843). Madri: Trotta, 2006.

KIERKEGAARD.S. Mi punto de vista (1846). Madrid: Aguilar, 1988.

LIPOVETSKY, G. A felicidade paradoxal. São Paulo: Companhia das Letras, 2007.

MANCEBO, D. Indivíduo e psicologia: gênese e desenvolvimentos atuais. In: MANCEBO, D.; JACÓ-VILELA, A. M. (Org.). Psicologia Social: abordagens socio-históricas e desafios contemporâneos. Rio de Janeiro: Eduerj, 2004. p. 3548.

SÁ, R. N; RODRIGUES, J. T. A questão do sujeito e do intimismo em uma perspectiva fenomenológico-hermenêutica. In: FEIJOO, A. M. L. C.; SÁ, R. N. (Org.). Interpretações fenomenológico-existenciais para o sofrimento psíquico na atualidade. Rio de Janeiro: IFEN, 2008. p. 35-54.

SARTRE, J. P. A Náusea (1938). Petrópolis, RJ: Vozes, 2000.

SARTRE, J. P. O Ser e o Nada: ensaio de ontologia fenomenológica (1943). Petrópolis, RJ: Vozes, 2001.

SARTRE, J. P. Questão de método (1960). In: . A crítica da razão dialética. Rio de janeiro: DP\&A, 2002.

SCHULTZ, D. P.; SCHULTZ, S. E. História da Psicologia Moderna (1969). São Paulo: Cultrix, 1992.

SILVA, F. L. Ética e Literatura em Sartre. São Paulo: UNESP, 2004.

STEIN, E. A questão do método na filosofia: um estudo do modelo heideggeriano. Porto Alegre: Movimento, 1983.

Recebido em: 24 de abril de 2012

Aceito em: 14 de agosto de 2013 